\title{
Nuclear Excitation by Electronic Transition - NEET
}

\author{
J.A. Becker
}

This article was submitted to International Conference on Nuclear Structure "Mapping the Triangle", Jackson Hole, WY, May 22-25, 2002

\section{June 10, 2002}

U.S. Department of Energy

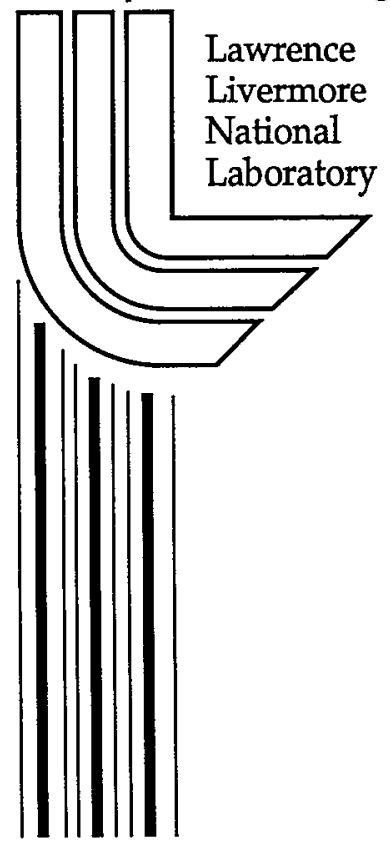




\section{DISCLAIMER}

This document was prepared as an account of work sponsored by an agency of the United States Government. Neither the United States Government nor the University of California nor any of their employees, makes any warranty, express or implied, or assumes any legal liability or responsibility for the accuracy, completeness, or usefulness of any information, apparatus, product, or process disclosed, or represents that its use would not infringe privately owned rights. Reference herein to any specific commercial product, process, or service by trade name, trademark, manufacturer, or otherwise, does not necessarily constitute or imply its endorsement, recommendation, or favoring by the United States Government or the University of California. The views and opinions of authors expressed herein do not necessarily state or reflect those of the United States Government or the University of California, and shall not be used for advertising or product endorsement purposes.

This is a preprint of a paper intended for publication in a journal or proceedings. Since changes may be made before publication, this preprint is made available with the understanding that it will not be cited or reproduced without the permission of the author.

This report has been reproduced directly from the best available copy.

Available electronically at http://www.doc.gov/bridge

Available for a processing fee to U.S. Department of Energy

And its contractors in paper from

U.S. Department of Energy

Office of Scientific and Technical Information

P.O. Box 62

Oak Ridge, TN 37831-0062

Telephone: (865) 576-8401

Facsimile: (865) 576-5728

E-mail: reports@adonis.osti.gov

Available for the sale to the public from

U.S. Department of Commerce

National Technical Information Service

5285 Port Royal Road

Springfield, VA 22161

Telephone: (800) 553-6847

Facsimile: (703) 605-6900

E-mail: orders@ntis.fedworld.gov

Online ordering: http://www.ntis.gov/ordering.htm

OR

Lawrence Livermore National Laboratory

Technical Information Department's Digital Library

http://www.llnl.gov/tid/Library.html 


\title{
Nuclear Excitation by Electronic Transition - NEET
}

\author{
J. A. Becker \\ Lawrence Livermore National Laboratory \\ Livermore, California 94550
}

\begin{abstract}
Experiments seeking to demonstrate nuclear excitation induced by synchrotron radiation have been enabled by the development of intense synchrotron radiation. The phenomena has been demonstrated in ${ }^{197} \mathrm{Au}$, while realistic upper limits for ${ }^{189}$ Os have been established. A new experiment in ${ }^{189} \mathrm{Os}$ is described. The experimental claim of NEET in isomeric ${ }^{178} \mathrm{Hf}$ is not credible.
\end{abstract}

\section{INTRODUCTION}

Nuclear excitation by electronic transition (NEET) is a rare decay mode for excited atomic states resulting in nuclear excitation. (Atomic states ordinarily decay via $x$-ray emission and Auger emission.) NEET requirements include energy degeneracy between the atomic and nuclear states, and the same transition multipolarity between the states. The development on intense beams of synchrotron radiation has enabled experiments designed to measure the probability of NEET ( $\mathrm{P}_{\mathrm{NEET}}$ ) induced by synchrotron radiation in nuclei where the NEET conditions are met. Rare as the phenomenon is, observation of NEET induced by synchrotron radiation has been reported by Kishimoto, et al. [1]. The focus of this manuscript is on describing the process, some recent experiments, and some ideas for future experiments.

\section{WHAT is NEET?}

Nuclear excitation through Electronic Excitation (NEET) was discussed by Morita in 1973 [2]. The two dominant decay processes for excited atomic states are x-ray emission and Auger electron emission. Exchange of a virtual photon induces NEET, a second order effect. The NEET probability is small, many orders of magnitude less than atomic excitation loss by $\mathrm{x}$-ray emission.

Fig. 1 isolates (schematically) NEET and gives the relevant formula in a selfevident notation. The matrix element is similar to the (inverse) internal conversion matrix element. Important conditions for NEET to occur include:

- An overlap of the approximately degenerate states

- Common multipolarity of the atomic and nuclear transitions

- $\Gamma_{1}>\Gamma_{2}$ (Widths of the initial and final atomic-hole states, respectively). 
The last condition allows NEET to compete with real photon emission. The width of the nuclear state is so small it is treated as zero in the expression for PNEET. The formula in Fig. 1 is given in [3]. Ahmad, et al., [4] independently motivate a similar formula.

Kishimoto, et al., [1] have made a marvelous experiment and find that $\mathrm{P}_{\mathrm{NEET}}$ is (5.0 $\pm 0.6) \times 10^{-8}$ of the $\mathrm{K} x$-ray emission rate in ${ }^{197} \mathrm{Au}$ for the $\mathrm{K} \rightarrow \mathrm{M}_{1}$ hole transition, while Ahmad, et al., [4] report an upper limit in ${ }^{189} \mathrm{Os}$ for the probability that a $\mathrm{K}$ vacancy results in nuclear excitation of ${ }^{189} \mathrm{Os}\left(\mathrm{E}_{\mathrm{x}}=69.5 \mathrm{keV}\right), \mathrm{P}_{\mathrm{NEET}}<3 \times 10^{-10}$. These experiments take advantage of the intense monochromatic beams available from $3^{\text {rd }}$ generation synchrotrons to prepare the ionized atom to optimize conditions for the observation of NEET. Both experiments are discussed below.

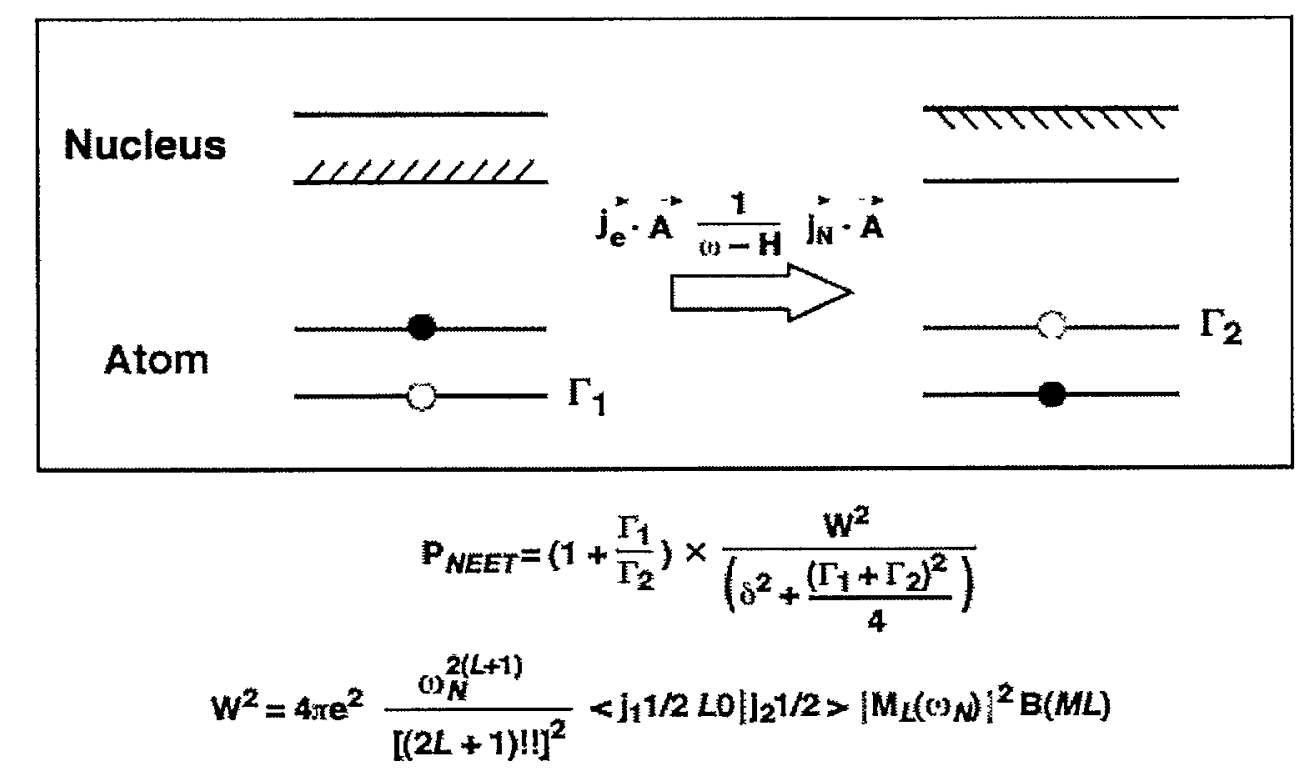

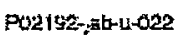

FIGURE 1. Schematic of NEET. The expression for the probability of NEET is given.

\section{RECENT NEET EXPERIMENTS}

\section{NEET in ${ }^{197} \mathrm{Au}$}

Kishimoto et al., [1] recently demonstrated the NEET effect in the nucleus ${ }^{197} \mathrm{Au}$. ${ }^{197} \mathrm{Au}$ has an (accidental) near degeneracy between the energy of the nuclear $1 / 2^{+}$state 
at $\mathrm{E}_{\mathrm{x}}=77.351 \mathrm{keV}$ and the atomic $\mathrm{K} \rightarrow \mathrm{M}_{1}$ hole transition $\left(1 \mathrm{~S}_{1 / 2} \rightarrow 3 \mathrm{~S}_{1 / 2}\right),(80.725 \rightarrow$ $3.425) \mathrm{keV}, \Delta \mathrm{E}_{\mathrm{ATOMIC}}=77.300$. The energy difference in the atomic configuration is $53 \mathrm{eV}$, and the atomic and nuclear transitions can have the same multipolarity.

Therefore, two important conditions for NEET are clearly realized: a near energy degeneracy between the nuclear and atomic transitions $(\Delta \mathrm{E}=51 \mathrm{eV})$, and common multipolarity for the transitions. Kishimoto, et al., irradiated ${ }^{197} \mathrm{Au}$ with monochromatic photons $(\Delta \mathrm{E}=19(2) \mathrm{eV})$ at several energies. They measured photon absorption at the nuclear resonance energy $77.351 \mathrm{keV}$ and also measured NEET at an incident photon energy $\mathrm{E}=80.989 \mathrm{keV}$ where they found the maximum yield. They report $\mathrm{P}_{\text {NEET }}=5.0$ (6) $\times 10^{-8}$ relative to the production of $\mathrm{K}$-vacancies. Measurements of both resonance absorption and of NEET allowed Kishimoto, et al., to use ratios to remove uncertainties in their report of $\mathrm{P}_{\mathrm{NEET}}$, and in particular to avoid a determination of detection efficiency. (A calculation of the $\mathrm{K}$-vacancy rate is however required.) The experimental signal of excitation of the nuclear state included measuring its decay with time, $t_{1 / 2}=1.9 \mathrm{~ns}$ for the $77.35 \mathrm{keV}$ state. The experimental result for NEET agrees with the recent calculations of Tkalya [5], who finds $\mathrm{P}_{\mathrm{NEET}} \sim 3.8 \times 10^{-8}$ and Harston [6], who finds $\mathrm{P}_{\mathrm{NEET}} \sim 3.6 \times 10^{-8}$.

\section{NEET in ${ }^{189}$ Os (I)}

Ahmad, et al., [4] searched for NEET in ${ }^{189}$ Os. They irradiated ${ }^{189}$ Os with an intense monochromatic beam of photons delivered at the Advance Photon Source (APS), sited at Argonne National Laboratory. The incident energy was $\mathrm{E}=98.74 \mathrm{keV}$, well above the Os K-edge at $73.9 \mathrm{keV}$. The atomic-nuclear degeneracy Ahmad, et al., attempted to take advantage of lies between the nuclear state at $\mathrm{E}_{\mathrm{x}}=69.537 \mathrm{keV}\left(\mathrm{J}^{\mathrm{\Pi}}=\right.$ $5 / 2^{-}$) and the $\mathrm{KM}_{\mathrm{I}}$ transition $(70.822 \mathrm{keV}, \mathrm{M} 1)$. (There are also nearby $\mathrm{E} 2$ atomic transitions where the energy overlap is not as good.) The NEET condition for energy degeneracy is not as well satisfied in this case as in the ${ }^{197} \mathrm{Au}$ case: $\Delta \mathrm{E}(\mathrm{keV})=70.822$ $-69.537=1.285$, while in ${ }^{197} \mathrm{Au} \Delta \mathrm{E}(\mathrm{keV})=0.051$. The experimental signal for NEET was not the direct decay of the $69.54 \mathrm{keV}$ state, but rather the more easily observed and definitive decay of the $30.814 \mathrm{keV}$ isomeric state in ${ }^{189} \mathrm{Os}\left[\mathrm{J}^{\pi}=9 / 2^{-}, \mathrm{t}_{1 / 2}\right.$ $\sim 5.7(1) \mathrm{h}]$, populated in the decay of the $69.54 \mathrm{keV}$ state. Ahmad, et al. did not observe NEET, reporting an upper limit $\mathrm{P}_{\mathrm{NEET}}<9 \times 10^{-10}$, a limit improved in a subsequent experiment to $\mathrm{P}_{\mathrm{NEET}}<3 \times 10^{-10}$ [7]. This result is consistent with the results of an independent experiment at the SPring- 8 synchrotron radiation facility, where Aoki et al. [ 8], report $\mathrm{P}_{\mathrm{NEET}}<4.1 \times 10^{-10}$. These limits are orders of magnitude below earlier experimental efforts. (See e.g., $[4,8]$ for references to the earlier work.)

What is expected for $\mathrm{P}_{\mathrm{NEET}}$ in these experiments on ${ }^{189}$ Os? Ahmad, et al., make use of the expression they develop to calculate $P_{\mathrm{NEET}}(\mathrm{M} 1)=1.3 \times 10^{-10}$, a value entirely consistent with their experimental result, and consistent with the measurement of Aoki, et al. The experimental upper limits are also consistent with two recent calculated values: $\mathrm{P}_{\mathrm{NEET}}=1.2 \times 10^{-10}[5]$, and $\mathrm{P}_{\mathrm{NEET}}=1.1 \times 10^{-10}[6]$. 


\section{NEET in ${ }^{189}$ Os (II)}

An experiment planned for late summer 2002 at LLNL takes advantage of the LLNL Electron Beam Ion Trap Facility (EBIT) [9]. Ionized ${ }^{189} \mathrm{Os}$ is prepared by bombardment with a variable energy electron beam and contained within the ion trap. The energy of the electron beam is carefully controlled and tuned so that the sum of the energies of the bombarding electron beam and the L-shell ionized ${ }^{189}$ Os (a freebound transition) adds up to the excitation of the nuclear ${ }^{189} \mathrm{Os}$ level at $216.6 \mathrm{keV}$. Trapped ions are periodically gathered up and counted. The signal is the energy and decay rate of the $\mathrm{J}^{\mathrm{II}}=9 / 2^{-}, \mathrm{E}_{\mathrm{x}}=30.814 \mathrm{keV}, \mathrm{t}_{1 / 2}=5.7 \mathrm{~h}$ state, populated in the decay of the $216.6-\mathrm{keV}$ nuclear state. Observation of this experimental signal of NEET and not direct observation of the decay of the $216.6 \mathrm{keV}$ level improves confidence in any observed signal. Finally, since the energy degeneracy is accomplished by tuning the incident energy of the incident electron beam, observing an experimental signal while changing the electron-beam energy gives an opportunity for observing a resonance signal and improving confidence in the measurement.

\section{NEET in ${ }^{178} \mathbf{H f}$ ?}

Collins, et al., [10] have recently irradiated isomeric ${ }^{178} \mathrm{Hf}\left(\mathrm{J}^{\mathrm{I}}=16^{+} \mathrm{E}_{\mathrm{x}}=2.4 \mathrm{MeV}\right.$, $\left.\mathrm{t}_{1 / 2}=31 \mathrm{y}\right)$ at the SPring-8 facility. Incident monochromatic $(\Delta \mathrm{E}=0.5 \mathrm{eV}) \mathrm{x}$-ray energies were tuned between 9 and $13 \mathrm{keV}$, in steps of $\sim 5 \mathrm{eV}$. Enhanced $\gamma$-ray decay of the isomer near the incident x-ray energies of $11.3,11.7$, and $9.56 \mathrm{keV}$ are reported and ascribed to NEET, and a value of $P_{\text {NEET }}=2 \times 10^{-3}$ relative to L-shell photo ionization in this energy region reported. Attribution to NEET of this signal (if real) is extremely unlikely. This large magnitude of this result is clearly orders of magnitude greater than any reasonable theoretical calculation would predict for $\mathrm{P}_{\text {NEET }}$ (or for that matter, cross-section estimates based on photoabsorption). There is no evidence for the required nuclear level(s) completing the atomic-nuclear degeneracy with the appropriate multipolarity is completely lacking. The cross section claimed by Collins and coworkers [10] is also in complete disagreement with the experimental results of Ahmad, et al. [11], who report upper limits to the cross section for induced decay of isomeric ${ }^{178} \mathrm{Hf}$ irradiated by synchrotron radiation as a function of incident $\mathrm{x}$-ray energy. Conclusion: there is no credible evidence for observation of enhanced decay of isomeric ${ }^{178} \mathrm{Hf}$ induced by synchrotron radiation.

\section{SUMMARY}

There is interesting basic physics within the atomic-nuclear interaction. Measurements and understanding require a discipline oriented study in order to identify cases and circumstances where the small, second-order interactions can be turned to advantage and the effect observed. A more thorough discussion of nuclear transitions induced by synchrotron radiation has been given by Gemmell [12], and a brief discussion of the proposed nuclear excitation of ${ }^{189}$ Os using the EBIT facility has been given by Beiersdorfer, et al. [13]. 


\section{ACKNOWLEDGMENTS}

This work was funded in part by the U.S Department of Energy, and performed under the auspices of the U.S. Department of Energy by the University of California, Lawrence Livermore National Laboratory, Contract No. W-7405-Eng-48. This work was also supported in part by the U.S. Department of Energy Nuclear Energy Research Initiative (NERI).

\section{REFERENCES}

1. Kishimoto, S., et al,, Phys. Rev. Lett. 85, 1831 (2000)'.

2. Morita, M., Prog. Theor. Physics 49, 1574 (1973).

3. Meot, V., et al., EP 221.050.02, unpublished. The formula for NEET was developed by $\mathrm{D}$. Gogny and M. S. Weiss, private communication.

4. Ahmad, I., Dunford, R.W., Esbensen, H., Gemmell, D.S., Kanter, E.P., Rütt, U., and Southworth, S.H., Phys. Rev. C 61, 51304R (2000).

5. Tkalya, E.V., "Nuclear Excitation by Electronic Transition between Atomic Shells," in X-Ray and Inner-Shell Processes, edited by Dunford, R.W., Gemmell, D.S., Kanter, E.P., Krassig, B. and Southworth, S.H., AIP Conference Proceedings 506, Melville, New York, 2000 , pp. $486-495$. The value reported here for ${ }^{178} \mathrm{Hf}$ includes a small numerical factor. (Private communication to D. S. Gemmell.)

6. Harston, M.R., Nucl. Phys. A 690, 447 (2001).

7. Ahmad, I., Dunford, R.W., Gemmell, D.S., Lister, C.J., Siemssen, R.H., and Southworth, S.W., 2000, private communication.

8. Aoki, K., et al., Phys. Rev. C 64, 044609 (2001).

9. Marrs, E., Beiersdorfer, P., and Schneider, D., Physics Today 47, 27 (1994); Schneider, D., Hyperfine Interactions 99, 47(1996).

10. Collins, C.B., et al., Europhys. Lett. 57, 667 (2002).

11. Ahmad, I., Banar, J.C., Becker, J.A., Gemmell, D.S., Kraemer, A., Mashayekhi, A., McNabb, D.P., Miller, G.G., Moore, E.F., Pangault, L.N., Rundberg, R.S., Schiffer, J.P., Shastri, S.D., Wang, T-F., and Wilhelmy, J.B., Phys. Rev. Lett. 87, 072503 (2001).

12 Gemmell, D., in Proceedings of "X-Ray and Inner-Shell Processes", Rome, 2002, to be published.

13 Beiersdorfer, P., et al., in Proceedings of "X-Ray and Inner-Shell Processes", Rome, 2002, to be published. 